\title{
Nucleolar Fibrillar Material
}

National Cancer Institute

\section{Source}

National Cancer Institute. Nucleolar Fibrillar Material. NCI Thesaurus. Code C33182.

A thread-like complex of ribosomal components including ribosomal RNA, in various stages of transcription, and associated proteins. 